\title{
The frequency of refractive errors required to be corrected in childhood among Turkish children
}

\author{
Mahmut Atum $\odot^{1}$, Burçin Çakir $\odot^{1}$, Erdinç Bozkurt $\oplus^{2}$, Erkan Çelik $\oplus^{1}$, Gürsoy Alagöz $\oplus^{1}$ \\ 'Department of Ophthalmology, Sakarya University Education and Research Hospital, Sakarya, Turkey \\ ${ }^{2}$ Department of Ophthalmology, Kars Kafkas University, Kars, Turkey
}

\begin{abstract}
BACKGROUND: The aim of this study is to investigate the distribution of refractive errors needed to be correct in childhood.

MATERIAL AND METHODS: Children applied and received glasses prescriptions were recruited. Age, gender, spherical, cylindrical error, and spherical equivalent (SE) were noted. The refractive errors were classified as myopic, hyperopic and cylindrical errors according to the $\mathrm{SE}$ and prescriptions. Cylindrical errors were subdivided into myopic, hyperopic. Children were classified into 4 groups. Group 1, 2, 3 and 4 composed of children whose ages were between $0-5,6-10,11-15$ and 16-18 years, respectively.

RESULTS: There were 846 children in group 1, 3931 in group 2, 5948 in group 3, 3896 in group 4, and a total of 14621 children. The rates of myopia and hyperopia were $72.4 \%$ and $27.6 \%$. Myopic and hyperopic astigmatism were found in $29.1 \%$ and $11.3 \%$ of children. Myopia, myopic astigmatism increased with age ( $\mathrm{p}<0.05)$. The hyperopia rate decreased with decreasing age $(\mathrm{p}<0.05)$. The frequency of myopia, myopic astigmatism was higher in both male and female children $(\mathrm{p}<0.05)$. The rate of myopia was higher in females $(\mathrm{p}<0.05)$. There was no statistically significant difference in terms of cylindrical value between genders. The statistically significant difference was found in terms of mean SE among all groups and a negative correlation was present between age and mean SE. A lower negative correlation was stated between age and cylindrical value.

CONCLUSION: Corrected myopic and myopic astigmatism errors were higher than hyperopic refractive errors. The prevalence of myopia increased by age and was higher in females. The need for glasses was highest in children whose age range was between 11 and 15 years.
\end{abstract}

KEY WORDS: refractive errors; astigmatism; myopia; hyperopia; childhood

Ophthalmol J 2020; Vol. 5, 33-37

\section{INTRODUCTION}

The most common cause of visual impairment worldwide is uncorrected refractive errors (myopia, hyperopia, and astigmatism). Approximately 153 million people are thought to be affected [1]. Uncorrected refractive errors may lead to amblyopia in childhood and cause persistent visual im- pairment. Refractive status should be checked in both preschool and school-age children [2]. Studies have been previously performed on the prevalence of refractive errors in childhood in different regions [2-5]. Rajavi et al. reported in a study conducted in Iran that they had 3.5\% hyperopia, $22.6 \%$ myopia and $4.9 \%$ astigmatism in children 
aged 7-12 years. They also observed an increase in myopia and decrease in hyperopia as the children aged [6]. Another study conducted in Germany also revealed an increase in myopia and decrease in hyperopia with age for patients between 2 and 35 years old [7]. The prevalence of myopia has been increasing steadily and is estimated to afflict approximately 1 billion people in the 2050 year according to a study by Holden et al. [8]. These studies reveal the refractive status of children, but not the refractive errors which need to be corrected. Mild hyperopia in children (below 3 diopters) without ocular deviation and with sufficient accommodation does not need to be corrected. Also, moderate myopia in preschool-aged children may be observed without intervention. Caca et al. investigated the refractive status of 21062 children and $22.7 \%$ needed correction of a refractive error. The age range was between 6-14 years [9]. The need for refractive error correction and the prevalence of corrected refractive errors in children is important to evaluate the real effect of refractive status on children's vision. To our knowledge, there is no study in the literature evaluating the prevalence of corrected refractive errors in children aged 0 to 18 years old.

\section{MATERIAL AND METHODS}

This study was conducted at the Departments of Ophthalmology of two major hospitals (Sakarya Training and Research Hospital, Yenikent State Hospital) in the Sakarya province in Turkey between January 2016 and December 2018. Prior approval from the Institutional Review Board (IRB number:71522473/050.01.04/19) was received and written informed consent was obtained from the parents of each participant. The study was performed in adherence to the Declaration of Helsinki.

Children between 0 to 18 years of age who were treated at the two hospitals and received a prescription for glasses after an ophthalmological examination were recruited for this study. Children with a previous history of refractive surgery were not included in this study.

All the children underwent a full ophthalmological examination including a best-corrected visual acuity measurement by Snellen chart, cycloplegic refraction, biomicroscopic examination for the anterior segment and fundus evaluation. Autorefractometers (Tonoref 3; Nidek Co., Ltd, Gamagori, Japan, and Canon RK-F2 Full Auto Ref-Keratometer; Canon, Tokyo, Japan) in the hospitals were used for measuring refractive errors. Examination for ocular deviation and dynamic retinoscopy was also performed. According to the results of the examination, a prescription for glasses was written and registered in the hospitals' information systems. The results of a dynamic retinoscopy and improvement in the best corrected visual acuity as the primary data used to determine if glasses should be prescribed to a child.

Age, gender, spherical and cylindrical errors, and spherical equivalent (SE) were noted. The SE was calculated as the sum of the spherical and half of the cylindrical value. Records of the glasses prescriptions were taken from the information systems and investigated retrospectively. The refractive errors were classified as myopic, hyperopic, and cylindrical errors according to the SE and prescriptions, respectively. Cylindrical errors were subdivided into myopic astigmatism and hyperopic astigmatism. The study was classified into four groups based on age range. Groups 1, 2, 3 and 4 were composed of children whose ages were between $0-5,6-10,11-15$, and $16-18$ years, respectively.

\section{STATISTICAL ANALYSIS}

Statistical analyses were performed using the SPSS program version 17 (SPSS Inc, Chicago, IL, USA). Descriptive statistics were used for data analyses. The Pearson correlation analysis was used for detecting the correlation between the refractive errors of the eyes of each child. Numerical data were given as mean \pm standard deviation. Distribution according to age and gender was given as a percentage. Kolmogorov-Smirnov analysis was used for testing the normality of distribution. Parametric tests (the Student $t$ test) were used for variables with normal distribution and non-parametric tests (Mann-Whitney $U$ test) were chosen for variables without normal distribution. A p value of $<0.05$ was considered statistically significant.

\section{RESULTS}

This current study was composed of 14621 children in total, if which $5656(38.7 \%)$ were female and $8965(61.3 \%)$ were male. The mean ages of males and females were $11.58 \pm 4.26$ and $12.70 \pm 3.85$ years, respectively, and the overall mean age was $12.27 \pm 4.05$ years. A statistically significant difference was present in terms of the mean ages of male and female children $(p<0.05)$. As mentioned in the materials and methods section, the children were divided into 4 groups. There were 846 (5.8\%) 


\begin{tabular}{|c|c|c|c|c|c|c|c|}
\hline & Myopia & Hyperopia & Total & $\begin{array}{c}\text { Myopic } \\
\text { astigmatism }\end{array}$ & No astigmatism & $\begin{array}{l}\text { Hyperopic } \\
\text { astigmatism }\end{array}$ & Total \\
\hline $\begin{array}{l}\text { Group } 1 \\
(0-5 \text { y) }\end{array}$ & $\begin{array}{c}135 \\
(16.0 \%)\end{array}$ & $\begin{array}{c}711 \\
(84.0 \%)\end{array}$ & $\begin{array}{c}846 \\
(100.0 \%)\end{array}$ & $\begin{array}{c}138 \\
(16.3 \%)\end{array}$ & $\begin{array}{c}372 \\
(44.0 \%)\end{array}$ & $\begin{array}{c}336 \\
(39.7 \%)\end{array}$ & $\begin{array}{c}846 \\
(100.0 \%)\end{array}$ \\
\hline $\begin{array}{l}\text { Group } 2 \\
(6-10 y)\end{array}$ & $\begin{array}{c}2211 \\
(56.2 \%)\end{array}$ & $\begin{array}{c}1720 \\
(43.8 \%)\end{array}$ & $\begin{array}{c}3931 \\
(100.0 \%)\end{array}$ & $\begin{array}{c}1034 \\
(26.3 \%)\end{array}$ & $\begin{array}{c}2119 \\
(53.9 \%)\end{array}$ & $\begin{array}{c}778 \\
(19.8 \%)\end{array}$ & $\begin{array}{c}3931 \\
(100.0 \%)\end{array}$ \\
\hline $\begin{array}{l}\text { Group } 3 \\
(11-15 y)\end{array}$ & $\begin{array}{c}4817 \\
(81.0 \%) \\
\end{array}$ & $\begin{array}{c}1131 \\
(19.0 \%)\end{array}$ & $\begin{array}{c}5948 \\
(100.0 \%)\end{array}$ & $\begin{array}{c}1769 \\
(29.7 \%)\end{array}$ & $\begin{array}{c}3788 \\
(63.7 \%)\end{array}$ & $\begin{array}{c}391 \\
(6.6 \%) \\
\end{array}$ & $\begin{array}{c}5948 \\
(100.0 \%)\end{array}$ \\
\hline $\begin{array}{l}\text { Group } \\
4(16-18)\end{array}$ & $\begin{array}{c}3426 \\
(87.9 \%)\end{array}$ & $\begin{array}{c}470 \\
(12.1 \%)\end{array}$ & $\begin{array}{c}3896 \\
(100.0 \%)\end{array}$ & $\begin{array}{c}1315 \\
(33.8 \%)\end{array}$ & $\begin{array}{c}2436 \\
(62.5 \%)\end{array}$ & $\begin{array}{c}145 \\
(3.7 \%)\end{array}$ & $\begin{array}{c}3896 \\
(100.0 \%)\end{array}$ \\
\hline $\begin{array}{l}\text { Total } \\
(0-18)\end{array}$ & $\begin{array}{c}10589 \\
(72.4 \%)\end{array}$ & $\begin{array}{c}4032 \\
(27.6 \%)\end{array}$ & $\begin{array}{c}14621 \\
(100.0 \%)\end{array}$ & $\begin{array}{c}4256 \\
(29.1 \%)\end{array}$ & $\begin{array}{c}8715 \\
(59.6 \%)\end{array}$ & $\begin{array}{c}1650 \\
(11.3 \%)\end{array}$ & $\begin{array}{c}14621 \\
(100.0 \%)\end{array}$ \\
\hline Male & $\begin{array}{c}3771 \\
(66.7 \%)\end{array}$ & $\begin{array}{c}1885 \\
(33.3 \%)\end{array}$ & $\begin{array}{c}5656 \\
(100.0 \%)\end{array}$ & $\begin{array}{c}1815 \\
(32.1 \%)\end{array}$ & $\begin{array}{c}3001 \\
(53.1 \%)\end{array}$ & $\begin{array}{c}840 \\
(14.9 \%)\end{array}$ & $\begin{array}{c}5656 \\
(100.0 \%)\end{array}$ \\
\hline Female & $\begin{array}{c}6818 \\
(76.1 \%)\end{array}$ & $\begin{array}{c}2147 \\
(23.9 \%)\end{array}$ & $\begin{array}{c}8965 \\
(100.0 \%)\end{array}$ & $\begin{array}{c}2441 \\
(27.2 \%)\end{array}$ & $\begin{array}{c}5714 \\
(63.7 \%)\end{array}$ & $\begin{array}{c}810 \\
(9.0 \%)\end{array}$ & $\begin{array}{c}8965 \\
(100.0 \%)\end{array}$ \\
\hline
\end{tabular}

children in group 1, group 2 included 3931 (26.9\%) children, Group 3 included 5948 (40.7\%) children, and there were 3896 (26.6\%) children in Group 4. A high positive correlation was found between the two eyes of children and the data obtained from the right eye were used in the analyzes $(r=0.814$, $\mathrm{p}=0.000$ ).

Myopia was present in 10,589 (72.4\%) children and hyperopia was present in $4032(27.6 \%)$ children. Myopic astigmatism was found in 4256 (29.1\%) children and $1650(11.3 \%)$ children had hyperopic astigmatism. In 8715 (59.6\%) children astigmatism was not present.

While the myopia rate was $16 \%$ and the myopic astigmatism rate was $16.3 \%$ in Group 1, these rates were $87.9 \%$ and $33.8 \%$ in Group 4, respectively. It was observed that myopia and myopic astigmatism increased with age $(\mathrm{p}<0.05)$. The rates of hyperopia and hyperopic astigmatism were $84.0 \%$ and $39.7 \%$ in Group 1 and $12.1 \%$, and $3.7 \%$ in Group 4 , respectively. The hyperopia rate decreased with age $(\mathrm{p}<0.05)$.

The distribution of corrected refractive errors in all age groups and genders is summarized in Table 1. When the distribution of refractive errors according to gender was investigated, the frequency of myopia and myopic astigmatism was higher than hyperopia and hyperopic astigmatism in both male and female children $(\mathrm{p}<0.05)$. In addition, the rate of myopia was higher in females $(\mathrm{p}<0.05)$.

The mean SE was $-0.65 \pm 2.22$ diopter $(\mathrm{D})$ and ranged between $-17.50 \mathrm{D}$ and $+18.00 \mathrm{D}$. The mean cylindrical value was $-0.16 \pm 0.90 \mathrm{D}$ and ranged

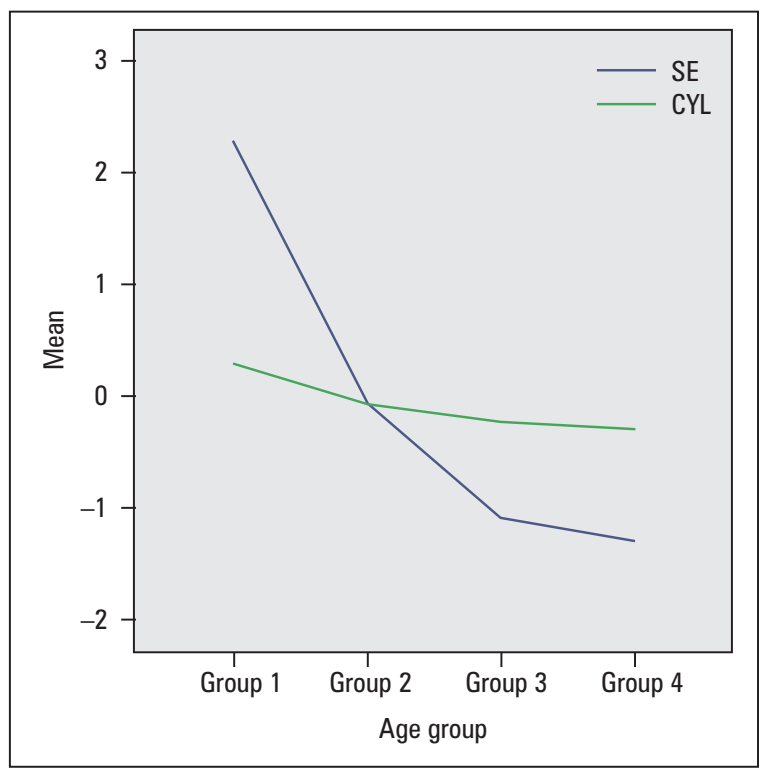

FIGURE 1. Mean values of refraction errors according to age groups in diopters (Group 1: $0-5$ years, Group 2: 6-10 years, Group 3: $11-15$ years and Group 4: 16-18 years). D — diopter; SE — spherical equivalent; CYL — cylinder

between $-7.00 \mathrm{D}$ and +6.25 D. A statistically significant difference was found in terms of mean SE among all groups and a negative correlation was present between age and the mean SE $(r=-0.375$, $\mathrm{p}<0.05)$. Similarly, a lower negative correlation was stated between age and cylindrical value $(r=-0.162$, $\mathrm{p}<0.05$ ) (Fig. 1).

The mean SE and cylindrical value were $-0.43 \pm 2.45 \mathrm{D}$ and $-0.15 \pm 1.03 \mathrm{D}$ in males and 


\begin{tabular}{|l|c|c|c|c|c|c|}
\hline \multicolumn{2}{|l|}{ Table 2. Comparison of spherical equivalent (SE) and cylinder (CYL) values according to age groups } \\
\multicolumn{2}{|c|}{} & $\begin{array}{c}\text { Group 1 } \\
\text { (n= 846) }\end{array}$ & $\begin{array}{c}\text { Group 2 } \\
(\mathbf{n}=\mathbf{3 9 3 1 )}\end{array}$ & $\begin{array}{c}\text { Group 3 } \\
\text { (n= 5948) }\end{array}$ & $\begin{array}{c}\text { Group 4 } \\
\text { (n= 3896) }\end{array}$ & p \\
\hline Mean SE (D) & Lower & $2.25 \pm 2.76$ & $-0.05 \pm 2.30$ & $-1.07 \pm 1.88$ & $-1.26 \pm 1.77$ & $<0.05$ \\
\hline \multirow{2}{*}{$95 \%$ Cl for Mean SE } & Upper & 2.06 & -0.12 & -1.12 & -1.32 & \\
\hline Mean CYL (D) & & $0.31 \pm 1.25$ & $-0.06 \pm 1.09$ & $-0.21 \pm 0.78$ & $-0.29 \pm 0.69$ & $<0.05$ \\
\hline \multirow{2}{*}{$95 \%$ Cl for Mean CYL } & Lower & 0.2312 & -0.0961 & -0.2369 & -0.3159 & \\
\cline { 2 - 7 } & Upper & -0.4012 & -0.0278 & -0.1971 & -0.2721 & \\
\hline
\end{tabular}

Group 1: 0-5 years, Group 2: 6-10 years, Group 3: 11-15 years and Group 4: $16-18$ years; D — diopter; SE — standard error; $\mathrm{Cl}$ - confidence interval

$-0.80 \pm 2.04 \mathrm{D}$ and $0.17 \pm 0.80$ in females, respectively. While the frequency of myopia was higher in females, there was no statistically significant difference in terms of cylindrical value between males and females ( $\mathrm{p}<0.05$ and $\mathrm{p}=0.363$, respectively). Table 2 summarizes the mean SE and cylindrical values classified according to age group.

\section{DISCUSSION}

This current study revealed the rate of corrected myopic and myopic astigmatism errors were higher than hyperopic refractive errors. Robaei et al. found the rate of 12-year-old Australian children requiring glasses was $19.0 \%$. The rates of myopia, hyperopia, and astigmatism were $46.3 \%, 10.9 \%$, and $21.8 \%$, respectively [10]. Gaete et al. found school-aged children needed glasses at a rate of $34.4 \%$. They did not investigate the distribution of refractive errors [11]. Robaei et al. also investigated the patterns of glasses use in 6-year-old Australian school children and found the rate of glasses use was $4.4 \%$. Hyperopia with or without astigmatism was the most frequent reason for glasses use (40.3\%) [12]. These reports supported our findings. We found a higher hyperopic corrected refractive error in children between 0 and 5 years old and this refractive error gradually decreased with age. We also observed the need for glasses was lower in children between 0 and 10 years old. This result indicated that hyperopic refractive errors were less often corrected. Huang et al. found myopia started in children at approximately 7 years old, increased with age, and had a significant association with visual acuity [13]. Gursoy et al. investigated refractive errors in 7- to 8-year-old children and the need for glasses for myopia and hyperopia were $0.8 \%$ and $1.0 \%$, respectively. The narrow and young age range may cause this result.
In this study, the need for glasses was $20.4 \%$ of all children [14].

When we investigated the rate of corrected refractive errors in children, we observed the need for glasses was highest in children whose age range was between 11 and 15 years (Group 3). The growth of children in this age range is faster than in other periods. Chen et al. found the prevalence of myopia exhibited an increased tendency with height development in children [15]. These factors may be responsible for our findings.

Glasses need for myopia was higher in girls than boys in this study. Lin et al. found a lower prevalence and lesser degree of myopia among boys. Goldschmidt et al. reported higher myopia prevalence in girls. But Alemam et al. found myopia was more prevalent in males. The behavioral differences of children in different regions may lead to these variations [16-18].

\section{CONCLUSION}

The need for glasses increased gradually by age 15 and a minimal decline was observed between 15and 18-year-old children. The prevalence of myopia increased with age and was higher in females. This current study is unique in terms of investigating the distribution of the need for glasses in childhood according to age, gender, and classification of refractive errors.

\section{Acknowledgments}

We are grateful to Atilla Akgül, one of the staff of the Sakarya Provincial Health Directorate, for his contributions to the data collection.

\section{Conflicts of interest}

The Authors declare that there is no conflict of interest. 


\section{REFERENCES}

1. Resnikoff S, Pascolini D, Mariotti SP, et al. Global magnitude of visual impairment caused by uncorrected refractive errors in 2004. Bull World Health Organ. 2008; 86(1): 63-70, doi: 10.2471/blt.07.041210, indexed in Pubmed: 18235892.

2. Tongue AC. Refractive errors in children. Pediatr Clin North Am. 1987; 34(6): 1425-1437, doi: 10.1016/s0031-3955(16)36365-9, indexed in Pubmed: 3317238.

3. Maul E, Barroso S, Munoz SR, et al. Refractive Error Study in Children: results from La Florida, Chile. Am J Ophthalmol. 2000; 129(4): 445-454, doi: 10.1016/s0002-9394(99)00454-7, indexed in Pubmed: 10764851.

4. Mehari ZA, Yimer AW. Prevalence of refractive errors among schoolchildren in rural central Ethiopia. Clin Exp Optom. 2013; 96(1): 65-69, doi: 10.1111/j.1444-0938.2012.00762.x, indexed in Pubmed: 22784031.

5. Gomez-Salazar F, Campos-Romero A, Gomez-Campaña H, et al. Refractive errors among children, adolescents and adults attending eye clinics in Mexico. Int J Ophthalmol. 2017; 10(5): 796-802, doi: 10.18240/ ijo.2017.05.23, indexed in Pubmed: 28546940.

6. Rajavi Z, Sabbaghi H, Baghini AS, et al. Prevalence of Amblyopia and Refractive Errors Among Primary School Children. J Ophthalmic Vis Res. 2015; 10(4): 408-416, doi: 10.4103/2008-322X.176909, indexed in Pubmed: 27051485.

7. Jobke $S$, Kasten $E$, Vorwerk $C$. The prevalence rates of refractive errors among children, adolescents, and adults in Germany. Clin Ophthalmol. 2008; 2(3): 601-607, doi: 10.2147/opth.s2836, indexed in Pubmed: 19668760.

8. Holden BA, Fricke TR, Wilson DA, et al. Global Prevalence of Myopia and High Myopia and Temporal Trends from 2000 through 2050. Ophthalmology. 2016; 123(5): 1036-1042, doi: 10.1016/j. ophtha.2016.01.006, indexed in Pubmed: 26875007.

9. Caca I, Cingu AK, Sahin A, et al. Amblyopia and refractive errors among school-aged children with low socioeconomic status in southeastern Turkey. J Pediatr Ophthalmol Strabismus. 2013; 50(1): 37-43, doi: 10.3928/01913913-20120804-02, indexed in Pubmed: 22966784.
10. Robaei D, Kifley A, Rose KA, et al. Refractive error and patterns of spectacle use in 12-year-old Australian children. Ophthalmology. 2006; 113(9): 1567-1573, doi: 10.1016/j.ophtha.2006.02.066, indexed in Pubmed: 16857261.

11. Gaete MI, Lira RP, Lynch de Moraes LF, et al. [Association between the need for optical correction prescription and other ocular conditions in school children]. Arq Bras Oftalmol. 2007; 70(6): 949-952, doi: 10.1590/s0004-27492007000600012, indexed in Pubmed: 18235905.

12. Robaei D, Rose K, Kifley A, et al. Patterns of spectacle use in young Australian school children: findings from a population-based study. J AAPOS. 2005; 9(6): 579-583, doi: 10.1016/j.jaapos.2005.07.005, indexed in Pubmed: 16414527.

13. Huang YoP, Singh A, Lai LiJu. The Prevalence and Severity of Myopia among Suburban Schoolchildren in Taiwan. Ann Acad Med Singapore. 2018; 47(7): 253-259, indexed in Pubmed: 30120433.

14. Gursoy H, Basmak H, Yaz Y, et al. Vision screening in children entering school: Eskisehir, Turkey. Ophthalmic Epidemiol. 2013; 20(4): 232-238, doi: 10.3109/09286586.2013.808672, indexed in Pubmed: 23865604.

15. Chen J, Chen Z, Lin S, et al. Correlation analysis for school-age children's height and refractive errors. Adv Clin Exp Med. 2018; 27(8): 1125-1130, doi: $10.17219 /$ acem/78773, indexed in Pubmed: 30088701.

16. Goldschmidt E. [On the etiology of myopia. An epidemiological study]. Acta Ophthalmol (Copenh). 1968: Suppl 98, indexed in Pubmed: 4886009.

17. Mohammed Alemam A, Aldebasi MH, Rehmatullah A, et al. Prevalence of Myopia among Children Attending Pediatrics Ophthalmology Clinic at Ohud Hospital, Medina, Saudi Arabia. J Ophthalmol. 2018; 2018: 3708409, doi: $10.1155 / 2018 / 3708409$, indexed in Pubmed: 30524756

18. Lin LL, Shih YF, Tsai CB, et al. Epidemiologic study of ocular refraction among schoolchildren in Taiwan in 1995. Optom Vis Sci. 1999; 76(5): 275-281, doi: 10.1097/00006324-199905000-00013, indexed in Pubmed: 10375241. 